\title{
Letters in Applied NanoBioScience
}

\author{
www.NanoBioLetters.com
}

https://doi.org/10.33263/LIANBS83.597603

Original Research Article

Open Access Journal

Received: 02.08.2019 / Revised: 26.08.2019 / Accepted: 28.08.2019 / Published on-line: 29.08.2019

\section{Bio-fabricated CuO NPs as green catalyst towards remediation of environmental pollutants}

\author{
Boya Palajonnala Narasaiah ${ }^{1}$, Badal Kumar Mandal ${ }^{1, *}$ * \\ ${ }^{1}$ Trace Elements Speciation Research Laboratory, Department of Chemistry, School of Advanced Sciences, Vellore Institute of Technology (VIT), Vellore 632014, Tamil \\ Nadu, India
}

\begin{abstract}
We report the fabrication of biogenic $\mathrm{CuO}$ NPs by green chemistry concept using agriculture waste durva grass extract as stabilizing and capping agent. The green methods offer few advantageous over the common physical and chemicals procedures due to easy, fast and eco-friendly i.e. without using costly and hazardous chemicals. The synthesized $\mathrm{CuO}$ NPs were characterized using different instrumental techniques such as UV-Vis, IR, XRD and TEM. UV-Vis spectroscopy confirmed the presence of CuO NPs by SPR peak at $299 \mathrm{~nm}$. Fourier transform infrared spectroscopy FTIR) identified the characteristic functional groups of synthesised CuO NPs as well as extract and Powder-XRD conformed for the crystalline nature of CuO NPs. The morphology of the synthesized CuO NPs was monitored by transmission electron microscopy (TEM). In addition, we have performed photocatalytic activity towards pollutant dyes such as Rhodamine B and Congo red. Our study results suggest that the synthesized CuO NPs exhibited good catalytic activity and it could be promising material for the removal/degradation of pollutants dye from waste water
\end{abstract}

Keywords: Agro-waste Durva grass, CuO NPs, Photocatalytic activity, Pollutant Dyes; Rhodamine B, Congo red.

\section{INTRODUCTION}

In the last decades nanoparticles (NPs) and nanocatalysts have become very promising materials in nanochemistry, because of smaller size with high surface area favors enhanced catalytic activity with respect to bulk materials. Predominantly copper oxide NPs (CuO NPs) has various applications in the nanotechnology due to their good catalytic activity and antibacterial properties [1, 2]. The properties of NPs mainly depend on their size, shape, structure, composition and morphologies [3]. These tiny particles have been synthesized by physical, chemical and biological methods [4, 5, 6]. These are expensive methods and require high temperature, pressure and energy since other reagents and solvents used are potentially hazardous to the environment and biological systems. Hence an ecofriendly process for the synthesis of NPs which does not use hazardous toxic chemicals is needed urgently [7, 8]. Synthesis of NPs using plants as a possible alternative method to physical and chemical process are considered due to environmentally ecofriendly and using nontoxic solvents and reagents [9]. The synthesis of metal NPs using various plants extracts including watermelon rind is reported [10]. The uses of $\mathrm{CuO}$ NPs are very important for its incredible and selective catalytic activity [11]. Nowadays residual organic dyes in effluents of different industries such as textiles, paper, paints, printing, plastic, pharmaceutical, cosmetic, medicine, food industries are a global concern. The textile industries play a major role in the economy of the USA and the associated countries. It accounts for the largest spending of dyestuffs@80\% taking overall account, which amounts about to 80000 tons in India. India ranks second after China in the export business of dyestuff. Actually, about $10^{5}-10^{6}$ tons of synthetic dyes produced annually are released into the environment as wastewaters globally. Being hazardous to the environment even 1 $\mathrm{mg} / \mathrm{L}$ of dye can cause serious problems to environments. Dyes contaminated wastewater is toxic, poisonous, dangerous, and carcinogenic to living beings [12]. Hence the international environmental standards have become more and more technological dependent for the removal of organic pollutants such as dyes. Thus the remediation of all unwanted dyes i.e. Methylene blue (MB), Congo red (CR), Rhodamine B (Rh-B) and Methyl orange (MO) in waste water is a challenging task to the environmentalists.

The various methods accessible for the degradation of organic pollutants such as biological, physical, and chemical techniques including aerobic, anaerobic, coagulation, chemical oxidation, membrane separation, electrochemical treatment, dilution, filtration, ion exchange and RO membranes are active in waste water treatments with regard to removal of dye stuff [13-15]. Many techniques have been widely applied in wastewater treatments but they are associated with some drawbacks for their applications. Hence safe and cheap technologies are highly preferable for remediation. Recently enhanced catalytic degradation of pollutants finds some importance in the treatment of wastewater generated from industrial and living sources $[16,17]$. Among different catalysts nanocatalysts have undergone enormous growth in recent years and seem to be an emerging material in the field of catalysis in the near future [18].

The present study focused on the biosynthesis of copper oxide nanoparticles ( $\mathrm{CuO} \mathrm{NPs}$ ) from agro-waste durva grass aqueous extract for the first-time. The green-synthesized $\mathrm{CuO}$ NPs was used for the degradation of environmentally harmful dyes. Especially the ability of the synthesized $\mathrm{CuO}$ NPs as an efficient green photocatalyst in degrading Rhodamine B and Congo red was investigated by UV irradiation at room temperature in the present study. 


\section{EXPERIMENTAL SECTION}

\section{Materials.}

$\mathrm{Cu}\left(\mathrm{NO}_{3}\right)_{2} .3 \mathrm{H}_{2} \mathrm{O}$, Rhodamine $\mathrm{B}(\mathrm{RB})$, and Congo red $(\mathrm{CR})$ were purchased from Sigma-Aldrich, India. Distilled water was used as a solvent and all analytical grade reagents were used. Fresh durva grass was collected from the agriculture crop field of AP state, India.

Collection and Preparation of Durva Grass Aqueous Extract. The green durva grass was collected from sunflower crop cultivated agricultural land. After washing thoroughly durva grass was cut into small pieces and washed with hot water repeatedly to remove soluble matters, then dried in an oven at $60{ }^{\circ} \mathrm{C}$ for $3 \mathrm{~h}$. The oven-dried powder was sieved through 100 mesh sieve. $100 \mathrm{~mL}$ of distilled water containing $3 \mathrm{~g}$ powder was heated in a water-bath at $80{ }^{\circ} \mathrm{C}$ for $30 \mathrm{~min}$ to prepare aqueous extract. The extract was cooled, filtered through Waterman filter paper and was stored for the synthesis of $\mathrm{CuO}$ NPs.

\section{Synthesis of Copper Oxide Nanoparticles.}

$0.3624 \mathrm{~g}$ copper nitrate $(0.05 \mathrm{M})$ was dissolved in $30 \mathrm{~mL}$ double distilled water and then $30 \mathrm{~mL}$ of freshly prepared aqueous extract was added dropwise with stirring thoroughly at $70{ }^{\circ} \mathrm{C}$ for $3 \mathrm{~h}$. The colour change from light green to dark brown during the heating process was due to the surface Plasmon resonance of $\mathrm{CuO}$ NPs formed which was further confirmed by UV-Visible spectroscopy. The obtained colloidal solution was centrifuged at $5000 \mathrm{rpm}$ for $30 \mathrm{~min}$, then black precipitates were washed thrice with absolute ethanol followed by double distilled water to remove any biomolecules and impurities present. The obtained fine pellet was dried on a hot plate at $60{ }^{\circ} \mathrm{C}$ for $20 \mathrm{~min}$, crushed into powder and then was annealed at $500^{\circ} \mathrm{C} 3 \mathrm{~h}$ to get crystalline $\mathrm{CuO}$ NPs.

\section{Characterization of Synthesized CuO NPs.}

The preliminary characterization was carried out by a UV-Visible spectroscopy (Jasco V-670 UV-Visible double beam spectrophotometer). The absorption intensity of the synthesized colloidal $\mathrm{CuO}$ NPs solution was recorded in between wavelength range of 200 to $800 \mathrm{~nm}$, and the obtained data was re-plotted by using Origin 8.5 software.

FTIR analysis was carried out to detect the presence of functional groups in durva grass extract and on the surface of the synthesized $\mathrm{CuO}$ NPs. Separated dried $\mathrm{CuO}$ NPs was used for XRD and FTIR analysis. The purified dried $\mathrm{CuO}$ NPs was analysed using in $\mathrm{KBr}$

\section{RESULTS SECTION}

Initially the formation of $\mathrm{CuO}$ NPs indicated colour change from light yellow to dark brown and also the formation of $\mathrm{CuO}$ NPs was confirmed by UV-Visible spectroscopy where the absorbance of the NPs dispersion was monitored at $200 \mathrm{~nm}$ to 800 nm. Fig. 1(A) shows the clear surface Plasmon resonance (SPR) band at $299.75 \mathrm{~nm}$ which confirms the formation of $\mathrm{CuO}$ NPs. The photocatalytic activity of $\mathrm{CuO}$ NPs depends upon its optical band gap energy. Optical band gap energy of the synthesized CuO NPs was determined by Tauc equation (i).

$$
\alpha=C\left(h v-E_{g}\right)^{2} \ldots \ldots . .(i)
$$

pellets by Shimadzu IR AFFINITY-1 (JASCO FT-IR 4100) against durva grass powder as control in the diffuse reflectance mode at a resolution of $4 \mathrm{~cm}^{-1}$. The XRD analysis of purified $\mathrm{CuO}$ NP was carried out by using a Bruker D8 Advance diffractometer with $\mathrm{Cu} \mathrm{K} \alpha$ radiation $\left(\lambda=1.54 \AA\right.$, scanning range ( $2 \theta$ value) of $10^{\circ}$ to $90^{\circ}$, scanning rate of $4^{\circ} / \mathrm{min}$ and step size of $0.02^{\circ}$ ).

The high resolution transmission electron microscopy (HR-TEM) checked the size and shape of the synthesized $\mathrm{CuO}$ NPs. The selected area electron diffraction (SAED) pattern was recorded using a JEOL-JEM 2100 transmission electron microscope with an acceleration voltage of $200 \mathrm{kV}$. Initially $15 \mathrm{mg} \mathrm{CuO} \mathrm{NPs} \mathrm{pure}$ solid powder was dispersed in $2 \mathrm{~mL}$ absolute ethanol by sonication for $10 \mathrm{~min}$ using an ultrasonic bath for microscopic analysis. The TEM samples of CuO NPs were prepared by placing a drop of solution on the lacey carbon coated copper grids followed by evaporation of solvents from grids at ambient conditions for TEM analysis.

Dynamic light scattering (DLS) study was carried out to determine Zeta potential in predicting the stability of $\mathrm{CuO}$ NPs in aqueous dispersion by using Horiba scientific nanoparticci (nanoparticles analyzer, SZ-100). The suspension was measured in cell culture medium at $25{ }^{\circ} \mathrm{C}$ and $150 \mathrm{~V}$ in triplet for each sample. Also, polydispersity indexes (PDI) was determined at $20{ }^{\circ} \mathrm{C}$ with a scattering angle of $173^{\circ}$ in triplicate. Deionized water was used as a source of dispersing medium, while standard Malvern-50 v was used to calibrate instrument before analysis of samples.

\section{Photocatalytic Activity of CuO NPs.}

The photocatalytic activity of synthesized CuO NPs was carried out in an aqueous medium against degradation of organic dyes Rhodamine B (Rh-B) and Congo red (CR) by using Heber multilamp photoreactor under UV irradiation $(\lambda \max 254 \mathrm{~nm})$ at $125 \mathrm{~W}$ and low-pressure. $60 \mathrm{~mL}$ dye $(10 \mathrm{mg} / \mathrm{L})$ in $100 \mathrm{~mL}$ capacity of quartz tube was continuously stirred under dark in the absence of catalyst; the variation in absorption intensity was monitored by UV-Visible spectroscopy. The second phototube containing $60 \mathrm{~mL}$ dye solution $(10 \mathrm{mg} / \mathrm{L})$ with different doses of $\mathrm{CuO}$ NPs $(10,20,30 \mathrm{mg})$ was irradiated with UV light inside photoreactor. The photodegradation of organic dyes was observed by measuring absorption intensity of the dye solution at regular time intervals within $\lambda_{\max }$ of $200-800 \mathrm{~nm}$.

where, $\alpha$ is the absorption coefficient, $\mathrm{C}$ is the constant, ho is the photon energy and $\mathrm{E}_{\mathrm{g}}$ is the optical band gap energy respectively. Fig. 1(B) shows the UV-Vis DRS plot of the synthesized $\mathrm{CuO}$ NPs where a plot is drawn keeping $(\alpha h v)^{2}$ as Y-axis vs. hv as Xaxis. The band gap energy $\left(\mathrm{E}_{\mathrm{g}}\right)$ of $\mathrm{CuO}$ NPs is calculated by using the formula (i) as $2.62 \mathrm{eV}$ which suggests its semiconducting property.

The measurement of zeta potential value was determined by using photon correlation spectroscopy (PCS) i.e. dynamic light scattering (DLS) study. The zeta potential value of CuO NPs' 
dispersion was $-39.7 \mathrm{mV}$. The high negative value indicates that $\mathrm{CuO}$ NPs repelled to each other in dispersion resulting high elctrophoretic mobility of NPs which prevented aggregation/agglomeration of NPs [19]. The higher zeta potential values result in higher dispersion or more stability in solution (Fig. 1C).

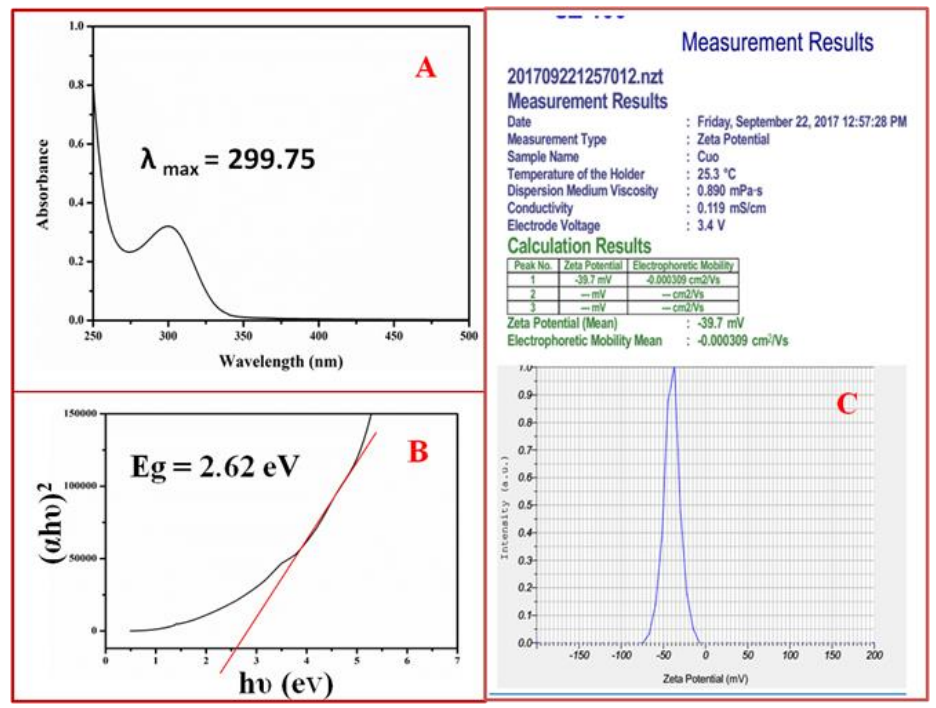

Figure 1. UV-Visible absorption spectrum of the synthesized $\mathrm{CuO}$ NPs (A), UV-DRS plot of CuO NPs (B), DLS spectrum of CuO NPs for Zeta potential analysis $(\mathrm{C})$.

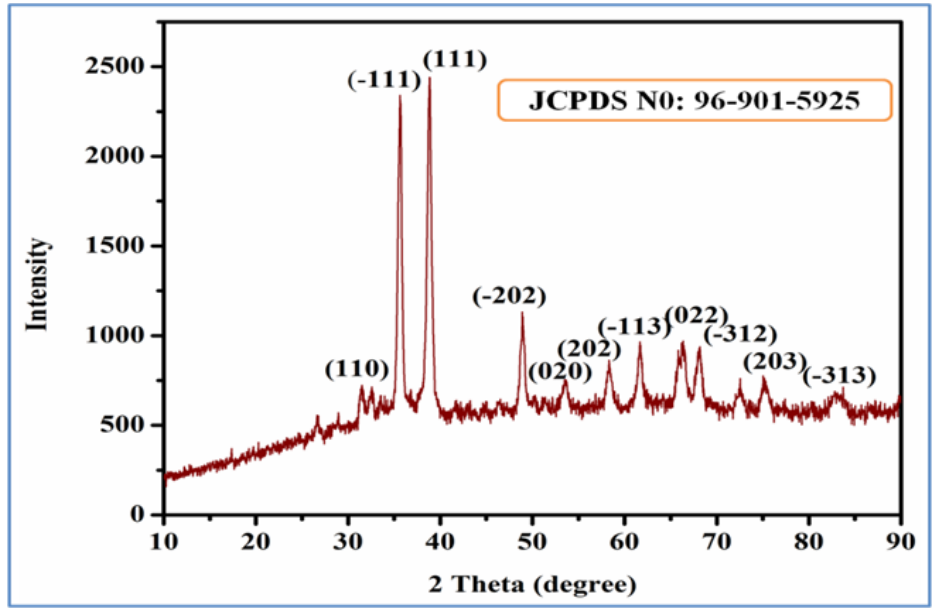

Figure 2. XRD pattern of the synthesized $\mathrm{CuO}$ NPs using durva grass aqueous extract.

X-ray diffraction study was performed to get information on crystallinity and phase formation as well as purity of nanomaterials. X-ray diffraction pattern of the synthesized $\mathrm{CuO}$ NPs is shown in Fig. 2. XRD pattern shows characteristic reflections peaks at hkl values of (110), (-111), ((111), (-202), (020), (202), (-113), (022), (203), (-313) suggesting FCC crystal structure with lattice parameter "a" of $4.09 \AA$ [20]. The (111) lattice plane is more intense because of its predominant orientation than other peaks and the broaden Bragg's peaks indicate the formation of smaller crystallites. The obtained XRD pattern is compared with JCPDS data card (JCPDS N0: 96-901-5925) which confirms crystalline nature of the synthesized $\mathrm{CuO}$ NPs.

The average crystallite size is calculated by using Scherrer equation as

$$
\mathrm{D}=\mathrm{K} \lambda / \beta \operatorname{Cos}(\theta)
$$

Where $\mathrm{D}$ is the average crystal size, $\lambda$ is $\mathrm{X}$-ray wave length ( $\lambda$ $\left.=1.5406 \mathrm{~A}^{0}\right), \mathrm{K}$ is the Scherrer coefficient $(0.891), \beta$ is the full width at half maximum intensity (FWHM) in radians, and $\theta$ is

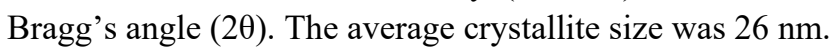

Fig. 3(A) shows the FTIR spectrum of the synthesized $\mathrm{CuO}$ NPs and durva grass aqueous extract was also analysed to investigate biomolecules present in durva grass extract responsible for the synthesis of $\mathrm{CuO}$ NPs and stabilization of NPs via surface capping of biomolecules on its surfaces [21]. FTIR spectrum (Fig. $3 \mathrm{~B})$ of the plant extracts shows predominant bands at 3280.92, 2922.91, 1732.08, $1570.06 \mathrm{~cm}^{-1}, 1072.42$, and $457.13 \mathrm{~cm}^{-1}$. The broad band around $3100-3600 \mathrm{~cm}^{-1}$ corresponds to $-\mathrm{OH}$ stretching frequency of polyphenolic compounds, glucose or NH- stretching of amino acid and proteins. The band at 2850-2950 $\mathrm{cm}^{-1}$ corresponds to alkyl C-H stretching frequency, band at 1732.08 $\mathrm{cm}^{-1}$ corresponds to carbonyl of carbohydrates. The band at 434.62 $\mathrm{cm}^{-1}$ corresponds to metal-oxygen $(\mathrm{Cu}-\mathrm{O})$ stretching vibration of CuO NPs (Fig. 3A).

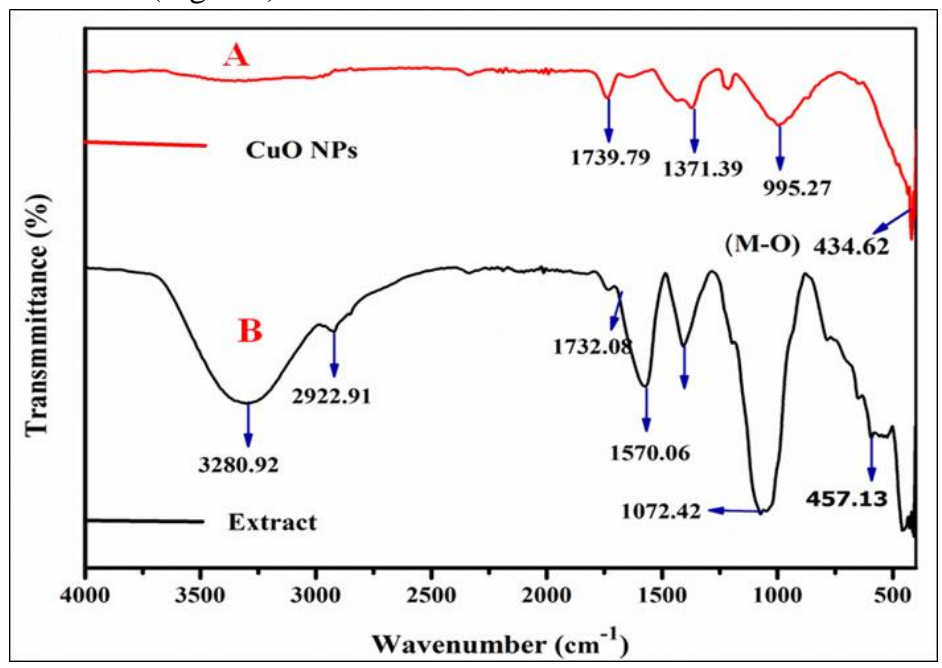

Figure 3. FTIR spectra of the synthesized $\mathrm{CuO}$ NPs (A) and durva grass aqueous extract (B).

Fig. 4 demonstrates the TEM, HR-TEM, SAED pattern and EDX (energy dispersive X-ray) micrographs of the synthesized $\mathrm{CuO}$ NPs. Fig. 4(A) exhibits particles size distribution and the majority of $\mathrm{CuO}$ NPs was within $30-45 \mathrm{~nm}$ with a mean diameter of $35 \mathrm{~nm}$ which supports the crystallite/grain size obtained from the XRD diffraction pattern by using Scherrer's equation (Fig. 4B). Fig. 4(C) shows the inter-planar distance i.e. d-spacing value of $0.264 \mathrm{~nm}$ which corresponds to lattice spacing (111) plane. Fig. 4(D) shows SAED pattern where bright spots are arranged in the form of concentric circles indicating the polycrystalline nature of CuO NPs [22]. Fig. 4(E) shows EDX spectrum of $\mathrm{CuO}$ NPs which basically check the purity of the NPs by analyzing chemical composition of the sample. It clearly shows that the atomic $\%$ and weight $\%$ of Copper are 56.01 and 43.02; atomic $\%$ and weight $\%$ of Oxygen are 83.49 and 16.51 respectively. The above results suggest that $\mathrm{CuO}$ NPs are pure and polycrystalline in nature. Fig. $4(\mathrm{~F})$ shows the particles size distribution within the range of 15-90 $\mathrm{nm}$ with a mean diameter of $35 \mathrm{~nm}$.

\section{Photocatalytic Degradation of Dyes.}

Several industries discharge a huge amount of toxic chemicals including coloring agents which are light sensitive. Among all colouring agents, Rh-B and CR are more stable organic substances with heterocyclic aromatic rings [23, 24]. Heterocyclic 
aromatic rings exhibit strong resistance to heat and light. Environmentally nanoparticles are considered to be less toxic and have high photocatalytic activity with large surface areas. Among different M/MO NPs (Table 1), CuO NPs with high photocatalytic activity is studied extensively towards degradation of Rh-B and CR dyes under UV irradiation.
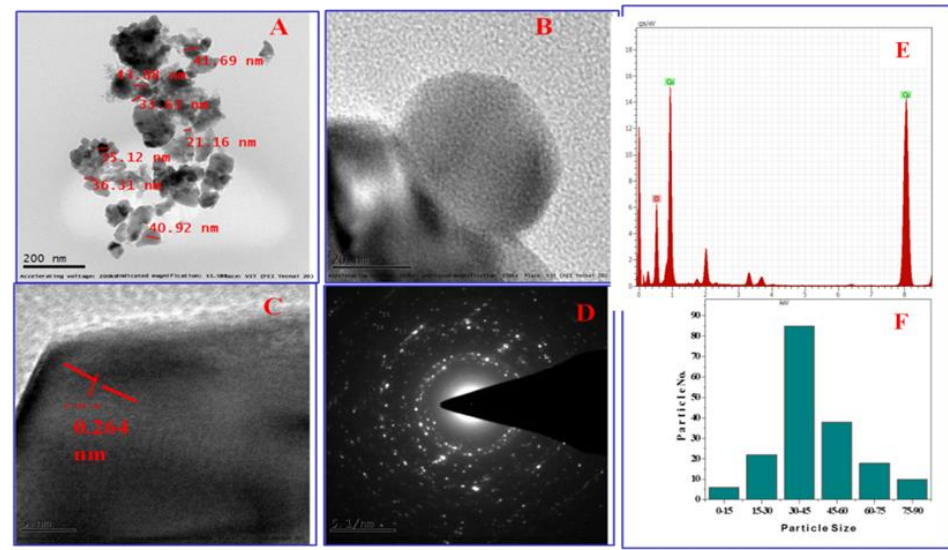

Figure 4. HR-TEM micrographs of $\mathrm{CuO}$ NPs at $200 \mathrm{~nm}$ magnification (A), $20 \mathrm{~nm}$ magnification (B), $5 \mathrm{~nm}$ magnification (C), SAED pattern of $\mathrm{CuO}$ NPs (D), EDX spectrum of CuO NPs (E) and particles size distribution of $\mathrm{CuO}$ NPs by DLS (F).

The photocatalytic degradation of Rh-B and $\mathrm{CR}$ dyes was evaluated by the photocatalyst $\mathrm{CuO}$ NPs in a photoreactor fitted with UV multilamp (125 W, $\lambda_{\max } 254 \mathrm{~nm}$ ). $20 \mathrm{mg} \mathrm{CuO} \mathrm{NPs} \mathrm{was}$ added to $60 \mathrm{~mL}$ dye $(10 \mathrm{mg} / \mathrm{L})$ solution with stirring for $30 \mathrm{~min}$ at room temperature to reach adsorption-desorption equilibrium under UV irradiation (125 W, $254 \mathrm{~nm})$. All dye samples were collected every $10 \mathrm{~min}$ intervals after UV irradiation for $90 \mathrm{~min}$ until colorless solution of Rh-B dye and monitored by UV-Vis spectroscopy (Fig. 5A).
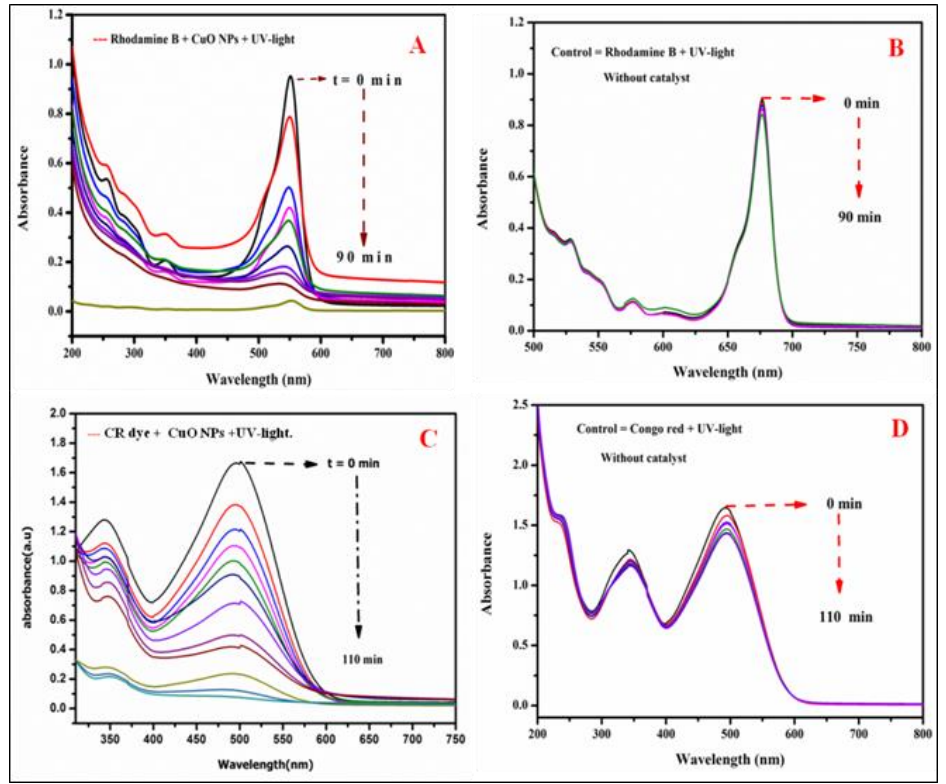

Figure 5. Degradation of Rh-B dye by catalyst $\mathrm{CuO}$ NPs (A) and without catalyst $\mathrm{CuO}$ NPs (B), degradation of CR dye by catalyst $\mathrm{CuO}$ NPs (C) and without catalyst (D) under UV irradiation.

The dye degradation was monitored by UV-Visible spectroscopy at $665 \mathrm{~nm}$ for Rh-B and at $556 \mathrm{~nm}$ for CR dye respectively. All samples were collected every $10 \mathrm{~min}$ intervals up to $110 \mathrm{~min}$ until a complete colorless solution of CR dye (Fig. 5C). Also, the degradation of dyes was measured by UV-Visible spectroscopy without catalyst as the control sample. There was no change in absorbance value of dye without catalyst $\mathrm{CuO}$ NPs (Fig. 5B\&D).

Fig. 6(A\&B) shows the effect of catalyst doses $(10,20$, and $30 \mathrm{mg}$ ) on degradation kinetics of dyes. The degradation rate of $\mathrm{Rh}-\mathrm{B}$ and $\mathrm{CR}$ dyes was increased with an increase in catalyst dose $[25,26]$. Also, degradation efficiency was increased i.e. time taken for degradation decreased with higher catalyst dose.

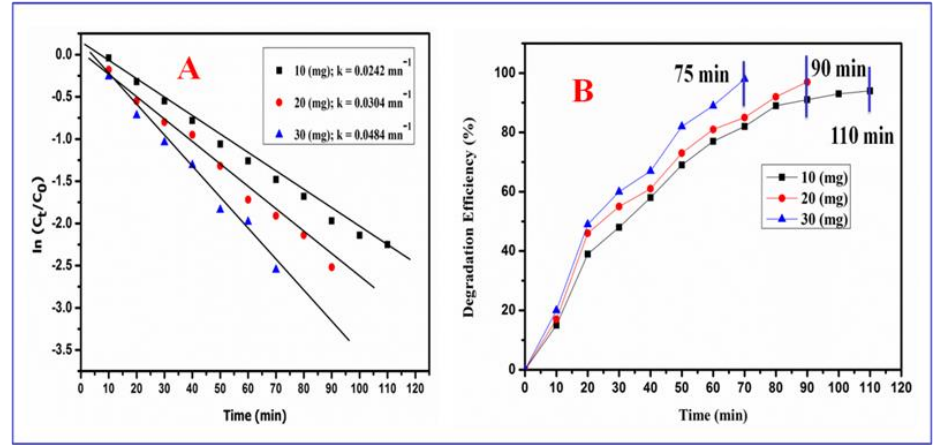

Figure 6. Effect of catalyst dose on degradation of Rh-B dye: First order linear plot of $\ln \left(\mathrm{C}_{\mathrm{t}} / \mathrm{C}_{0}\right)$ vs. time (min) (A), degradation efficiency $(\%)$ of Rh-B dye (B).

The degradation efficiency of Rh-B and CR was calculated by using the following formula as Degradation of Dye $(\%)=\left[\left(\mathrm{C}_{0^{-}}\right.\right.$ $\left.\mathrm{C}_{\mathrm{t}}\right) * 100 / \mathrm{C}_{\mathrm{o}}$, where $\mathrm{C}_{0}$ and $\mathrm{C}_{\mathrm{t}}$ are a concentration of dye at time 'zero' and time ' $\mathrm{t}$ ' respectively. The obtained results show that $98 \%$ of Rh-B degraded within 90 min and $95 \%$ of CR degraded within 110 min which suggest that $\mathrm{CR}$ is a stronger organic dye than Rh-B i.e. the catalyst $\mathrm{CuO}$ NPs degraded Rh-B quickly compare to $\mathrm{CR}$ degradation at a particular dose of catalyst. The obtained results are compared with other reported literatures on dye degradation (Table 1).
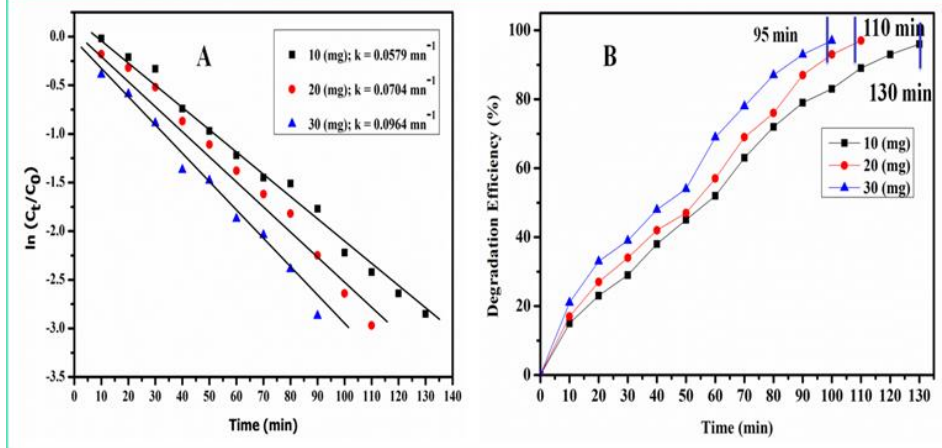

Figure 7. Effect of catalyst dose on photo-degradation of CR dye: First order linear plot of $\ln \left(\mathrm{C}_{\mathrm{t}} / \mathrm{C}_{0}\right)$ vs. time $(\mathrm{A})$, degradation efficiency $(\%)$ of CR dye (B).

The degradation efficiency of NPs depends on its size, surface area and morphology [27]. The degradation rate of dye was increased with NPs having lower band gap value which can readily generate electron-hole pairs easily available for photodegradation on UV irradiation like $\mathrm{CuO}$ NPs. Hole can highly oxidise the organic molecules into carbon dioxide and water molecules; while the excited electrons are scavenging by ' $\mathrm{O}_{2}$ ' in the environment forming super oxide which is a very strong oxidising agent. The photocatalytic degradation of dyes by photocatalyst $\mathrm{CuO}$ NPs depends on three important parameters i.e. size of CuO NPs, bandgap energy and nature of dyes. Normally, more number of aromatic ring, hetero-aromatic rings and azo dyes are strong/stable dyes such as CR dye which is stronger dye than Rh-B dye [28]. 
The photocatalytic activity $\mathrm{CuO}$ NPs follows the first order reaction in degrading $\mathrm{CR}$ and $\mathrm{Rh}-\mathrm{B}$ dyes and the rate of degradation is calculated by the following formula [29] as

$\ln (\mathrm{Ct})=\ln \left(\mathrm{C}_{0}\right)-\mathrm{Kt}$, where, $\mathrm{C}_{\mathrm{o}}$ is the initial concentration of dye, $C_{t}$ is the final concentration of dye at time ' $t$ ' and $k$ is the rate constant, respectively. Fig. 7 shows a graphical plot between $\operatorname{lnC}_{\mathrm{t}} / \mathrm{C}_{0}$ along $\mathrm{Y}$-axis vs. time (min) along $\mathrm{X}$-axis suggesting a decreasing trend under UV-irradiation for degradation of dyes. The rate constant ' $\mathrm{k}$ ' of $\mathrm{Rh}-\mathrm{B}$ and $\mathrm{CR}$ photodegradation was checked from the plots which are $0.0579,0.0704$ and $0.0964 \mathrm{~min}^{-1}$ for 10,20 and $30 \mathrm{mg}$ of catalyst mediated photodegradation, respectively (Fig. 7 A\&B). The obtained results clearly show that the value of rate constant was increased with increasing catalyst doses (Table 2).

\section{Photocatalytic Degradation Mechanism of Dye.}

Fig. 8 shows a plausible mechanism on photocatalytic degradation of $\mathrm{Rh}-\mathrm{B} / \mathrm{CR}$ dye using $\mathrm{CuO}$ NPs as photocatalyst under UV-irradiation. In the photodegradation process $\mathrm{CuO}$ NPs mediates reduction of oxygen to generate super oxide $\left({ }^{\circ} \overline{\mathrm{O}}_{2}\right)$ using excited conduction band electrons under UV-irradiation, while positive holes on valence band help to generate another reactive oxygen species hydroxyl radical ' $\mathrm{OH}$ ' after reduction of water molecules which causes photodegradation of toxic dyes [30]. The present results suggest degradation of toxic dyes to water molecules and carbon dioxide in the presence of $\mathrm{CuO}$ NPs as photocatalyst.

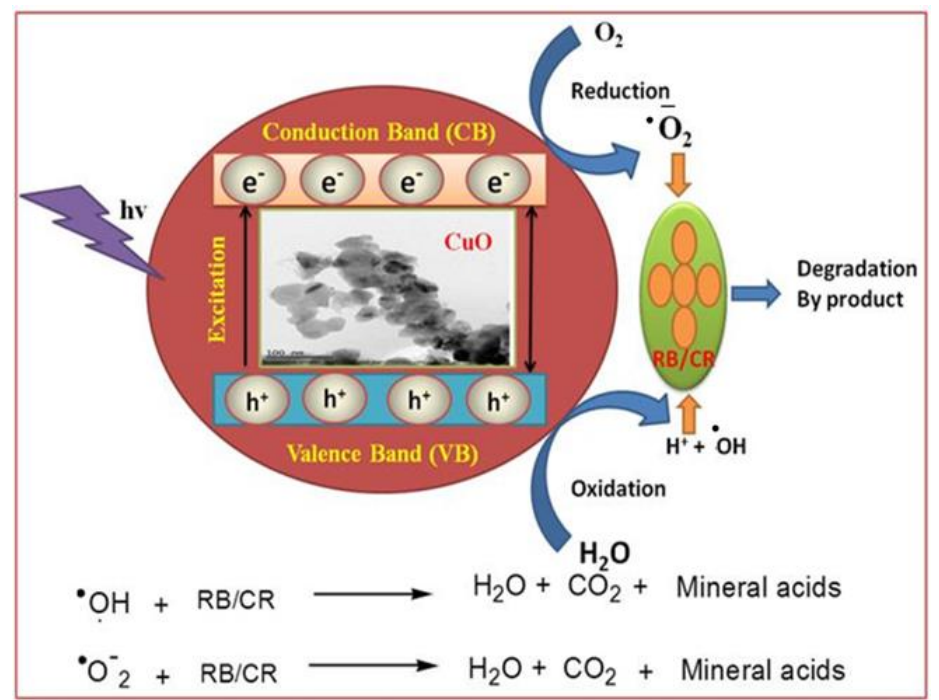

Figure 8. Possible mechanism on photocatalytic degradation of $\mathrm{RB} / \mathrm{CR}$ dye using $\mathrm{CuO}$ NPs as photocatalyst.

\section{CONCLUSIONS}

Our study reported the biosynthesis of $\mathrm{CuO}$ NPs by argowaste durva grass aqueous extract for the first time in literature. The synthesised CuO NPs was confirmed by UV-Visible, FTIR, XRD, HR-TEM and EDX while DLS was used for the stability study. Under UV-irradiation the synthesized $\mathrm{CuO}$ NPs showed good photocatalytic efficiency towards the degradation of CR and Rh-B dyes. The current study reports that the green synthesized $\mathrm{CuO}$ NPs could be used as an effective photocatalyst in degrading environmentally hazardous and toxic dyes in a greener way.

Table 1. Comparison of degradation efficiency of synthesized $\mathrm{CuO}$ NPs with other published reports on dye degradation.

\begin{tabular}{|c|c|c|c|c|}
\hline Dye name & Photo-catalyst & Time (min) & Deg. (\%) & References \\
\hline \multirow[t]{6}{*}{ Rh-B } & $\mathrm{CuO}$ NPs & 300 & 100 & [31] \\
\hline & CuO-nanowires & 660 & 95 & [32] \\
\hline & $\mathrm{CuO} / \mathrm{ZnO} \mathrm{NPs}$ & 150 & 83 & [33] \\
\hline & $\mathrm{CuO}$ nanostructures & 300 & 85 & [34] \\
\hline & $\mathrm{Fe}_{3} \mathrm{O}_{4} / \mathrm{Zn}-/ \mathrm{CuWO}_{4} \mathrm{NPs}$ & 210 & 99 & [35] \\
\hline & $\mathrm{CuO} \mathrm{NPs}$ & 90 & 98 & Present study \\
\hline \multirow[t]{6}{*}{ CR } & $\mathrm{Ba} / \mathrm{Alg} / \mathrm{CMC} / \mathrm{TiO}_{2}$ & 240 & 91 & [36] \\
\hline & $\mathrm{ZnO}$ NPs & 135 & 97 & [37] \\
\hline & Chitosan/nano-CdS & 180 & 85.9 & [38] \\
\hline & $\mathrm{WO}_{3} / \mathrm{TiO}_{2} / \mathrm{AC}$ & 120 & 95.21 & [39] \\
\hline & $\mathrm{CeO}_{2} \mathrm{NPs}$ & 100 & 95 & [40] \\
\hline & $\mathrm{CuO}$ NPs & 110 & 95 & Present study \\
\hline
\end{tabular}

Table 2. Effect of CuO NPs as photocatalyst on degradation of Rh-B and CR dyes.

\begin{tabular}{c|c|c|c|c|c} 
Dye & $\begin{array}{c}\text { Catalyst } \\
(\mathbf{m g})\end{array}$ & $\begin{array}{c}\text { Con. Dye } \\
(\mathbf{m g} / \mathbf{L})\end{array}$ & $\begin{array}{c}\text { Degradation } \\
\text { Time (min) }\end{array}$ & $\begin{array}{c}\text { \% of } \\
\text { degradation }\end{array}$ & $\begin{array}{c}\text { Rate Constant k } \\
\left(\mathbf{m i n}^{-1}\right)\end{array}$ \\
\hline Rh-B & 10 & 10 & 110 & 96 & 0.0242 \\
\hline & 20 & 10 & 90 & 98 & 0.0304 \\
\hline & 30 & 10 & 75 & 98 & 0.0484 \\
\hline CR & 10 & 10 & 130 & 93 & 0.0579 \\
\hline & 20 & 10 & 110 & 95 & 0.0704 \\
\hline & 30 & 10 & 95 & 96 & 0.0964
\end{tabular}

\section{REFERENCES}

1. Jin, Z.; Liu, C.; Qi, K.; Cui, X. Photo-reduced $\mathrm{Cu} / \mathrm{CuO}$ nanoclusters on $\mathrm{TiO}_{2}$ nanotube arrays as highly efficient and reusable catalyst. Sci. Rep. 2017, 7, 39695, https://doi.org/10.1038/srep39695.
2. Azam, A.; Ahmed, A.S.; Oves, M.; Khan, M.S.; Memic, A. Size-dependent antimicrobial properties of $\mathrm{CuO}$ nanoparticles against Gram-positive and-negative bacterial strains. Int. J. Nanomed. 2012, 7, 3527, https://doi.org/10.2147/IJN.S29020. 
3. Cuenya, B.R. Synthesis and catalytic properties of metal nanoparticles: Size, shape, support, composition, and oxidation state effects. Thin Solid Films 2010, 518, 3127-3150, https://doi.org/10.1016/j.tsf.2010.01.018.

4. Padovini, D.S.S.; Pontes, D.S.L.; Dalmaschio, C.J.; Pontes, F.M.; Longo, E. Facile synthesis and characterization of $\mathrm{ZrO}_{2}$ nanoparticles prepared by the AOP/hydrothermal route. Rsc Adv. 2014, 4, 38484-38490, https://doi.org/10.1039/C4RA04861J.

5. Coker, V.S.; Bennett, J.A.; Telling, N.D.; Henkel, T.; Charnock, J.M.; Van der Laan, G.; Pattrick, R.A.; Pearce, C.I.; Cutting, R.S.; Shannon, I.J.; Wood, J. Microbial engineering of nanoheterostructures: biological synthesis of a magnetically recoverable palladium nanocatalyst. ACS Nano 2010, 4, 25772584, https://doi.org/10.1021/nn9017944.

6. Li, M.; He, W.; Liu, Y.; Wu, H.; Wamer, W.G.; Lo, Y.M.; Yin, J.J.; FD\&C Yellow No. 5 (Tartrazine) degradation via reactive oxygen species triggered by $\mathrm{TiO}_{2}$ and $\mathrm{Au} / \mathrm{TiO}_{2}$ nanoparticles exposed to simulated sunlight. J. Agric. Food Chem. 2014, 62,

https://doi.org/10.1021/jf5045052.

7. Habeeb, M.K. Biosynthesis of nanoparticles by microorganisms and their applications. Int. J. Adv. Sci. Technol. Res. 2013, 1, 44-51, http://dx.doi.org/10.1155/2011/270974.

8. Akhtar, M.S.; Panwar, J.; Yun, Y.S. Biogenic synthesis of metallic nanoparticles by plant extracts. ACS Sustain Chem. Eng. 2013, 1, 591-602, https://doi.org/10.1021/sc300118u.

9. Shamaila, S.; Sajjad, A.K.L.; Farooqi, S.A.; Jabeen, N.; Majeed, S.; Farooq, I. Advancements in nanoparticle fabrication by hazard free eco-friendly green routes. Appl. Mater. Today. 2016, 5, 150-199, https://doi.org/10.1016/j.apmt.2016.09.009.

10. Lakshmipathy, R.; Reddy, B.P.; Sarada, N.C.; Chidambaram, K.; Pasha, S.K. Watermelon rind-mediated green synthesis of noble palladium nanoparticles: catalytic application. Appl. Nanosci. 2015, 5, 223-228, https://doi.org/10.1007/s13204-0140309-2.

11.Jin, Z.; Liu, C.; Qi, K.; Cui, X. Photo-reduced Cu/CuO nanoclusters on $\mathrm{TiO}_{2}$ nanotube arrays as highly efficient and reusable catalyst. Sci. Rep. 2017, 7, 39695, https://doi.org/10.1038/srep39695.

12. Kant, R. Textile dyeing industry an environmental hazard. $\begin{array}{llll}\text { Natural } & \text { Sci. } & \text { 2012, } & 4,\end{array}$ https://doi.org/10.4236/ns.2012.41004.

13. Khodadadi, B.; Bordbar, M.; Nasrollahzadeh, M. Green synthesis of $\mathrm{Pd}$ nanoparticles at Apricot kernel shell substrate using Salvia hydrangea extract: catalytic activity for reduction of organic dyes.J. Colloid Interface Sci. 2017, 490, 1-10, https://doi.org/10.1016/j.jcis.2016.11.032.

14. Bhattacharjee, A.; Ahmaruzzaman, M. A novel and green process for the production of tin oxide quantum dots and its application as a photocatalyst for the degradation of dyes from aqueous phase. J. Colloid Interface Sci. 2015, 448, 130-139, https://doi.org/10.1016/j.jcis.2015.01.083.

15. Ajmal, A.; Majeed, I.; Malik, R.N.; Idriss, H.; Nadeem, M.A. Principles and mechanisms of photocatalytic dye degradation on $\mathrm{TiO}_{2}$ based photocatalysts: a comparative overview. Rsc $A d v$. 2014, 4, 37003-37026, https://doi.org/10.1039/C4RA06658H.

16. Sreelatha, S.; Velvizhi, G.; Reddy, C.N.; Modestra, J.A.; Mohan, S.V. Solid electron acceptor effect on biocatalyst activity in treating azo dye based wastewater. $R S C A d v$. 2015, 5, 95926-95938, https://doi.org/10.1039/c5ra15648c.

17. Ahmad, A.; Mohd-Setapar, S.H.; Chuong, C.S.; Khatoon, A.; Wani, W.A.; Kumar, R.; Rafatullah, M. Recent advances in new generation dye removal technologies: novel search for approaches to reprocess wastewater. RSC $A d v$. 2015, 5, 3080130818, https://doi.org/10.1039/C4RA16959J.
18. Gao, J.F.; Li, H.Y.; Pan, K.L.; Si, C.Y. Green synthesis of nanoscale zero-valent iron using a grape seed extract as a stabilizing agent and the application for quick decolorization of azo and anthraquinone dyes. RSC Adv. 2016, 6, 22526-22537, https://doi.org/10.1039/C5RA26668H.

19. Kumar, K.M.; Mandal, B.K.; Tammina, S.K. Green synthesis of nano platinum using naturally occurring polyphenols. RSC $A d v$. 2013, 3, 4033-4039, https://doi.org/10.1039/C3RA22959A. 20. Sadollahkhani, A.; Ibupoto, Z.H.; Elhag, S.; Nur, O.; Willander, M. Photocatalytic properties of different morphologies of $\mathrm{CuO}$ for the degradation of Congo red organic dye. Ceram. Int. $\quad \mathbf{2 0 1 4}, 40, \quad$ 11311-11317, https://doi.org/10.1016/j.ceramint.2014.03.132.

21. Tamuly, C.; Saikia, I.; Hazarika, M.; Das, M.R. Reduction of aromatic nitro compounds catalyzed by biogenic $\mathrm{CuO}$ nanoparticles. $R S C \quad A d v$. 2014, 4, 53229-53236, https://doi.org/10.1039/C4RA10397A.

22. Mott, D.; Galkowski, J.; Wang, L.; Luo, J; Zhong, C.J. Synthesis of size-controlled and shaped copper nanoparticles. Langmuir 2007, 23, 5740-5745, https://doi.org/10.1021/la0635092.

23. Malwal, D.; Gopinath, P. Enhanced photocatalytic activity of hierarchical three dimensional metal oxide@ $\mathrm{CuO}$ nanostructures towards the degradation of Congo red dye under solar radiation. Catal. Sci. Technol. 2016, 6, 4458-4472, https://doi.org/10.1039/C6CY00128A.

24. Rahman, Q.I.; Ahmad, M.; Misra, S.K.; Lohani, M. Effective photocatalytic degradation of rhodamine $\mathrm{B}$ dye by $\mathrm{ZnO}$ nanoparticles. Mater. Lett. 2013, 91, 170-174, https://doi.org/10.1016/j.matlet.2012.09.044.

25. Tammina, S.K.; Mandal, B.K. Tyrosine mediated synthesis of $\mathrm{SnO}_{2}$ nanoparticles and their photocatalytic activity towards Violet 4 BSN dye.J. Mol. Liq. 2016, 221, 415-421, https://doi.org/10.1016/j.molliq.2016.05.079.

26. Gautam, A.; Kshirsagar, A.; Biswas, R.; Banerjee, S.; Khanna, P.K.; Photodegradation of organic dyes based on anatase and rutile $\mathrm{TiO}_{2}$ nanoparticles. RSC Adv. 2016, 6, 27462759, https://doi.org/10.1039/C5RA20861K.

27. Mao, B.; An, Q.; Zhai, B.; Xiao, Z.; Zhai, S. Multifunctional hollow polydopamine-based composites $\left(\mathrm{Fe}_{3} \mathrm{O}_{4} / \mathrm{PDA} @ \mathrm{Ag}\right)$ for efficient degradation of organic dyes. RSC Adv. 2016, 6, 4776147770, https://doi.org/10.1039/C6RA05954F.

28. Kirankumar, V.S.; Sumathi, S. Structural, optical, magnetic and photocatalytic properties of bismuth doped copper aluminate nanoparticles. Mater. Chem. Phys. 2017, 197, 17-26, https://doi.org/10.1016/j.matchemphys.2017.05.021.

29. Khan, S.S. Enhancement of visible light photocatalytic activity of $\mathrm{CdO}$ modified $\mathrm{ZnO}$ nanohybrid particles. J. Photochem. Photobiol. 2015, 142, 1-7, https://doi.org/10.1016/j.jphotobiol.2014.11.001.

30. Naraginti, S.; Thejaswini, T.V.L.; Prabhakaran, D.; Sivakumar, A.; Satyanarayana, V.S.V.; Prasad, A.A. Enhanced photo-catalytic activity of $\mathrm{Sr}$ and $\mathrm{Ag}$ co-doped $\mathrm{TiO}_{2}$ nanoparticles for the degradation of Direct Green-6 and Reactive Blue-160 under UV \& visible light. Spectrochim. Act A. 2015, 149, 571-579, https://doi.org/10.1016/j.saa.2015.04.101.

31. Tadjarodi, A.; Akhavan, O.; Bijanzad, K. Photocatalytic activity of $\mathrm{CuO}$ nanoparticles incorporated in mesoporous structure prepared from bis (2-aminonicotinato) copper (II) microflakes. Trans. Nonferrous Met. Soc. China. 2015, 25, 3634-3642, https://doi.org/10.1016/S1003-6326(15)64004-3.

32. Wang, S.L.; Li, P.G.; Zhu, H.W.; Tang, W.H. Controllable synthesis and photocatalytic property of uniform $\mathrm{CuO} / \mathrm{Cu}_{2} \mathrm{O}$ composite hollow microspheres. Adv. Powder Technol. 2012, 230, 48-53, https://doi.org/10.1016/j.powtec.2012.06.051. 
33. Mehr, E.S.; Sorbiun, M.; Ramazani, A.; Fardood, S.T. Plantmediated synthesis of zinc oxide and copper oxide nanoparticles by using ferulago angulata (schlecht) boiss extract and comparison of their photocatalytic degradation of Rhodamine B (RhB) under visible light irradiation. J. Mater. Sci. Mater. Electron. 2018, 29, 1333-1340, https://doi.org/10.1007/s10854017-8039-3.

34. Zaman, S.; Zainelabdin, A.; Amin, G.; Nur, O.; Willander, M. Efficient catalytic effect of $\mathrm{CuO}$ nanostructures on the degradation of organic dyes. J. Phys. Chem. Solids. 2012, 73, 1320-1325, https://doi.org/10.1016/j.jpcs.2012.07.005.

35. Shekofteh-Gohari, M.; Habibi-Yangjeh, A. Fabrication of novel magnetically separable visible-light-driven photocatalysts through photosensitization of $\mathrm{Fe}_{3} \mathrm{O}_{4} / \mathrm{ZnO}$ with $\mathrm{CuWO}_{4}$. J. Ind. Eng. Chem. 2016, 44, 174-184, https://doi.org/10.1016/j.jiec.2016.08.028.

36. Thomas, M.; Naikoo, G.A.; Sheikh, M.U.D.; Bano, M.; Khan, F. Effective photocatalytic degradation of Congo red dye using alginate/carboxymethyl cellulose $/ \mathrm{TiO}_{2}$ nanocomposite hydrogel under direct sunlight irradiation. J. Photochem. Photobiol. 2016, 327, 33-43, https://doi.org/10.1016/j.jphotochem.2016.05.005.
37. Fowsiya, J.; Madhumitha, G.; Al-Dhabi, N.A.; Arasu, M.V. Photocatalytic degradation of Congo red using Carissa edulis extract capped zinc oxide nanoparticles. J. Photochem. Photobiol. 2016, 162, 395-401, https://doi.org/10.1016/j.jphotobiol.2016.07.011.

38.Zhu, H.; Jiang, R.; Xiao, L.; Chang, Y.; Guan, Y.; Li, X.; Zeng, G. Photocatalytic decolorization and degradation of Congo Red on innovative crosslinked chitosan/nano-CdS composite catalyst under visible light irradiation. J. Hazard. Mater. 2009, 169, 933-940, https://doi.org/10.1016/j.jhazmat.2009.04.037.

39. Sun, J.H.; Wang, Y.K.; Sun, R.X.; Dong, S.Y. Photodegradation of azo dye Congo Red from aqueous solution by the $\mathrm{WO}_{3}-\mathrm{TiO}_{2}$ /activated carbon (AC) photocatalyst under the UV irradiation. Mater. Chem. Phys. 2009, 115, 303-308, https://doi.org/10.1016/j.matchemphys.2008.12.008.

40. Latha, P.; Prakash, K.; Karuthapandian, S. Effective Photodegradation of CR \& MO dyes by morphologically controlled Cerium oxide nanocubes under visible light Illumination. Optik 2018, 154, 242-250, https://doi.org/10.1016/j.ijleo.2017.10.054.

\section{ACKNOWLEDGEMENTS}

The authors thank Vellore Institute of Technology, Vellore for the financial support, working platform and instrument facility given to complete the study. Especially, the authors thank Vellore Institute of Technology, Vellore for providing "VIT SEED GRANT" for carrying out this research work. 